\title{
Optimal design of helical reducers for cement equipment
}

\author{
Evgeniy Gudov ${ }^{1}$ and Sergey Lagutin ${ }^{2}$ \\ ${ }^{1}$ Deputy Chief Designer \\ ${ }^{2}$ Senior designer, Dr-Eng, \\ Elektrostal Heavy Engineering Works, Department of Chief Designer, Russia \\ Email: lagutin@eztm.ru
}

\begin{abstract}
The trends in raising the technical level of multistage helical reducers for drives of cement, metallurgical and other heavy equipment are considered. An interactive method for optimizing the geometrical parameters of reducers with various gear ratios is proposed, which ensures equal strength of the stages in contact and bending endurance. It is shown that an increase in the hardness of the teeth requires an increase of the module and helical angle of the teeth, limitation of gear ratios, and to reduce the difference in center distances of adjacent stages. When creating a new generation of reducers, the transition to gears with carburized teeth leads to an increase in load capacity of 2.5-3 times. The examples of gear drive design for rotary kilns and ball mills are considered.
\end{abstract}

Key words: helical reducer, contact and bending endurance, rotary kilns, ball mills.

\section{Introduction. The specifics of reducers for heavy equipment and their optimization issues}

The Elektrostal Heavy Engineering Works (EZTM) has accumulated a large theoretical and practical experience in creating reducers, primarily for drives of rolling and tube-rolling complexes operating under conditions of full process flow, as well as for drives of metallurgical, mining and other heavy equipment.

Due to the individual or small-scale nature of production, it is impossible to verify the performance characteristics of such reducers on the test benches. Operational parameters are guaranteed on the basis of engineering calculations, the reliability of which is ensured by a scientific approach, practical experience, as well as an archive containing several thousand projects of various reducers that are in long-term operation in difficult conditions of metallurgical workshops and mining careers.

When designing reducers, special attention is paid to the choice of the optimal kinematic scheme, ensuring equal strength of all stages, placement of gears in a housing with limited dimensions, maximum use of the internal volume of the housing. It is necessary to take into account the proximity of the input loads and the constant forcing of the operating modes during exploitation. Projects of unique gearboxes weighing up to 100 tons, designed to transmit up to $1500 \mathrm{kNm}$, are especially carefully developed.

The analysis of numerous designs of reducers, successfully operated in various machines, made it possible to trace certain trends in the approach to the design of reducers as a whole, as well as their components and parts [1-5]. In these works, in particular, it was shown that the main indicator of the technical level of general engineering application reducer should be its specific consumption of materials:

$$
\gamma=m / T_{\mathrm{n}},
$$

where $m$ is the weight of the reducer in tons, $T_{\mathrm{n}}$ is the nominal torque on the low-speed shaft, $\mathrm{kNm}$.

This indicator depends on many factors: the required design scheme, gear ratio, mode and service life, not least on the skills of the designing engineer, but, above all, from the current methods of thermal and mechanical treatment of the teeth.

Taking into account the technological capabilities of gear processing and thermal equipment, EZTM reducers, according to their technical level, can be roughly divided into the following four groups (Table $1)$.

In this table, $D_{\mathrm{e}}$ is the outside diameter of the largest gearwheel, $a_{\mathrm{wL}}$ is the center distance of the low-speed stage. The figures refer to single-flow double- or threestage cylindrical and bevel-cylindrical reducers.

Optimization in gear engineering can be performed at three levels: a single gear pair, a multi-stage reducer of a given type, and finally, the drive of the machine as a whole. The latter is beyond the scope of this paper, and the first two will be considered in more detail. 
Table 1. Technical level characteristics.

\begin{tabular}{|c|c|c|c|c|c|c|c|}
\hline № & Type of heat treatment & Finishing machining & $\begin{array}{c}D_{e} \\
\text { mm, } \\
\text { max. }\end{array}$ & $\begin{array}{l}a_{\mathrm{wL}}, \\
\mathrm{mm}, \\
\max .\end{array}$ & $\begin{array}{l}\text { Weght, } \\
\text { tons, } \\
\text { max. }\end{array}$ & $\begin{array}{c}\mathrm{T}_{\mathrm{n}}, \\
\mathrm{kNm}, \\
\max \end{array}$ & $\gamma$ \\
\hline 1. & $\begin{array}{l}\text { Carburizing } \\
\text { HRC 54...62 }\end{array}$ & Grinding of teeth & 1200 & 770 & 15 & 450 & $\begin{array}{l}0.025 \\
\ldots 0.05\end{array}$ \\
\hline 2. & $\begin{array}{l}\text { Surface hardening HFC, } \\
\text { HRC } 42 \ldots .55\end{array}$ & $\begin{array}{l}\text { Grinding or finishing } \\
\text { tooth hobbing }\end{array}$ & 1600 & 1000 & 20 & 280 & $\begin{array}{l}0.05 \\
\ldots 0.1\end{array}$ \\
\hline 3. & $\begin{array}{c}\text { Volume hardening } \\
\text { HB } 270 . .300\end{array}$ & Finishing tooth hobbing & 2800 & 1800 & 8 & 800 & $\begin{array}{l}0.10 \\
\ldots 0.2\end{array}$ \\
\hline 4. & $\begin{array}{c}\text { Normalizing } \\
\mathrm{HB} \leq 217\end{array}$ & Tooth hobbing & 8000 & - & - & - & $\geq 0.2$ \\
\hline
\end{tabular}

Optimization of the parameters of a single gear pair can be carried out by selecting the optimal geometric shape of the tooth flank, for which a treatment process must be developed. The criteria are geometric-kinematic indicators of the quality of the meshing (the reduced curvature, position and total length of contact lines, specific slip, various combinations of these indicators, determination of contact stresses and conditions for the formation of hydrodynamic lubrication, etc.) [6].

In this direction in the 1960s, after the appearance of the revolutionary work of M.L. Novikov, many studies were carried out. Their authors proposed the active tooth profile of the gearwheel or the basic rack in the form of a curve (cycloid, ellipse, sinusoid, etc.) and optimized it by varying the constants included in the equations of these curves. A common drawback of such gears is their low production effectiveness.

The involute gearing formed by the basic rack of a straight profile is easily reproduced by the grinding wheel, imposes less stringent requirements on the accuracy of assembly, and because of these advantages does not lose its positions, at least for special-purpose engineering.

We should notice that if optimization of the geometry of a gear with given dimensions and specified materials allows increasing its load capacity by $20-30 \%$, then the transition from thermally improved gears to gears hardened with high frequency currents (HFC) to a hardness of 45$50 \mathrm{HRC}$ doubles the load capacity. The hardening of teeth with the HFC made it possible to completely eliminate sticking that had previously occurred for some gears with a hardness of 240-280 HB, pinion tooth number $\mathrm{z} \leq 16$ and not very high precision of gear processing. Carburizing and hardening to a hardness of 60-62 HRC, subsequent by grinding the teeth, increases it by another 1.5-2 times. Therefore, the priority must be given to the technology and the geometry that satisfies it, and not vice versa.

At the same time, the possibility of optimizing the geometric parameters of a helical involute gearing is far from being exhausted. With the transition to harder materials, the ratio between the bending and contact strengths of the teeth changes, which requires finding the optimal values of the ratio of the module to the stage center distance, the helical angle of the teeth and the pressure angle in meshing. A change in the latter can be achieved by using new basic racks in serial production or large addendum modification in individual one.

\section{Optimization of the design parameters of multi-stage reducers}

In this case, the initial data, as a rule, are the torque at the low-speed shaft and the total gear ratio. The ratio of the central distances of the stages, the relative modulus and width of the wheels, the distribution of gear ratio between the stages are variable parameters. The minimum volume, weight, or moment of inertia is usually taken as criteria [1]. For real production conditions, the optimization process is complicated by the discreteness of the variable parameters (standard modules and center distances). Another circumstance complicating the optimization is the need to ensure in one housing the multiplicity of gear ratios

The load capacity of the multi-stage reducer as a whole is determined by the smallest of the recalculated to the low-speed shaft torques allowed by the bending and contact endurance of each of the stages. In the first approximation, the task of optimizing the basic geometric parameters (center distances, gear ratios and modulus of the stages) is reduced to equalizing these torques.

Developed on the basis of Russian standards GOST 21354-87 and GOST 16530-83, the software package Reduc 4.3 of geometric and strength calculation of cylindrical and bevel gears allows optimization in the interactive mode. With this approach, the strength calculation for the given main geometrical parameters is automated, and the user gives an estimate of the calculated option.

The initial data for the calculation are the parameters of the load and the mode of operation of the reducer, the geometrical parameters and accuracy of the stages, the characteristics of the material and the method of obtaining pinion and gearwheel blanks. The final results of the calculation 
are the values of torque on the low-speed shaft of each stage, allowable by the bending and contact endurance of its teeth. Contact and bending strengths are also checked on the maximum short-term overload. The deep contact endurance is determined for carburized gears.

According to the results of the first calculation, the initial data is adjusted and the calculation is repeated. After $3 \ldots 5$ adjustments, it is possible to equalize the torque values on the low-speed shaft of the reducer, allowed by the contact strength of each of the stages, as well as the bending strength of the low-speed stage with an accuracy of $20 \%$. Bending strength of high-speed and intermediate stages, as a rule, does not limit the load capacity of the reducer, as a whole.

\section{Mastering the market FOR cement equipment drives}

With the advent in the 1990s of new economic relations, EZTM is actively developing new markets for the supply of our products. In this regard, the market of equipment and spare parts for the Russian cement industry is of great interest to the plant. In the cement equipment, first of all, in the drive of furnaces and ball mills large cylindrical reducers with torque on the low-speed shaft from 150 to 1800 $\mathrm{kNm}$ are used. In Soviet times, they were produced mainly by the Volgocemmash plant and were also supplied by SKET (DDR) [7].

Since 2004, EZTM began to master the production of similar equipment. The development of this sector began with the delivery of spare parts for drive of rotary kilns and ball mills operating at various cement plants.
As spare parts for Symmetro-type double-flow reducers produced by Volgocemmash, EZTM repeatedly manufactured gear blocks of herringbone wheels with Novikov gearing - a complete set for the reducer A-2800 and high-speed units for the A-3600. Such blocks were supplied for JSC Shchurovsky Cement, Vostok-Cement, Maltsovsky Portland Cement, Kavkazcement and others.

We have mastered the production of spare herringbone gear units for such widely known reducers produced by the DDR as the ZM-1600 and $40 \mathrm{~A} 7$ of main drive for the $\varnothing 3 \times 14$ mills and D-3500 and DD-3500 for the $62.6 \times 13$ mills. In this case, we faced the fact that in the first modifications of these reducers, Zanderland gearing was used, which was cut on special gear-shaping machines with standard modules in face section, pressure angle $17^{\circ} 30^{\prime}$, helix angle $30^{\circ}$ and narrow $(\mathrm{b}=10 \mathrm{~mm})$ groove between half-crowns. Therefore, it was necessary to modernize these blocks, revise the parameters and compensate for the inevitable reduction in the width of half-crowns using higher-quality steels with higher heat treatment Upgraded gear units were supplied to Sebryakovcement, Belgorodsky cement and other enterprises.

In 2007, we designed and manufactured a threestage cylindrical reducer CT-3230 for the main drive of the new rotary kiln $\varnothing 4.5 \times 170$. Herringbone gears are made with volume hardening of teeth according to the degree of accuracy of 8-B GOST 1643-81. The reducer is powered by an engine with a capacity of $560 \mathrm{~kW}$, a rotational speed of $750 \mathrm{rpm}$. The gear ratio is $u_{\mathrm{s}}=116.7$, the rated torque on the output shaft $840 \mathrm{kNm}$ with a permissible overload of 1.5 times. This reducer has been installed and is successfully operated at "Krichevcementnoshifer" (Belarus) and then at other enterprises.

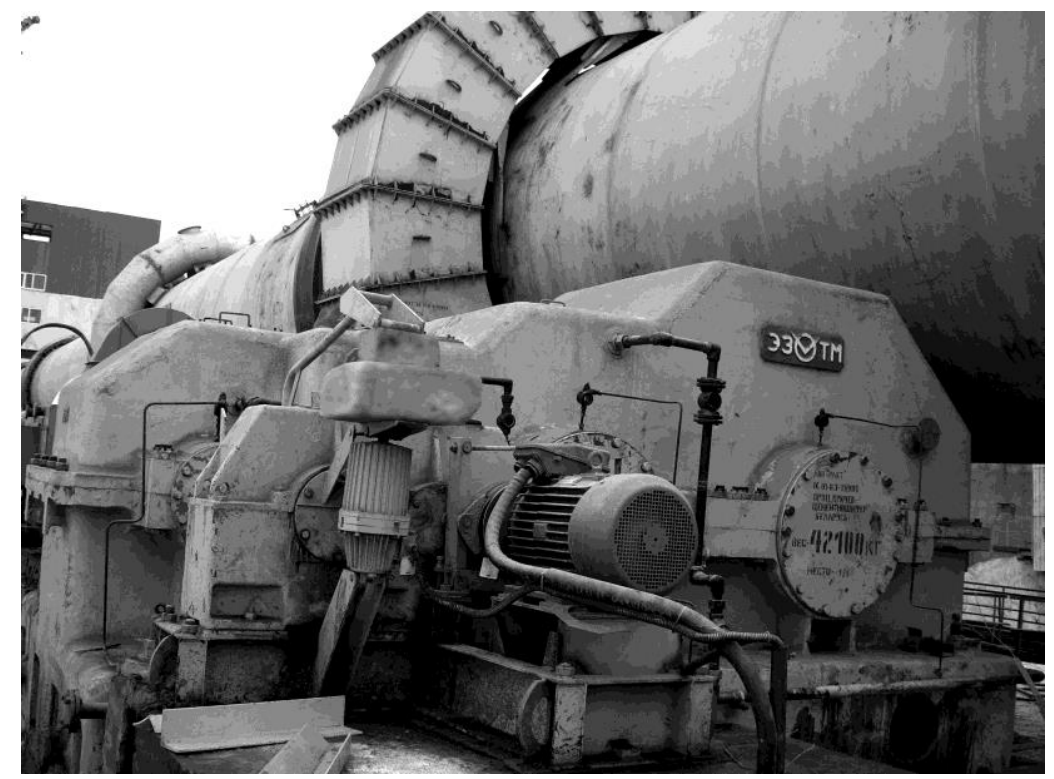

Fig 1. Drive of rotary kiln $\varnothing 4.5 \times 170 \mathrm{~m}$ with reducer CT-3230. 
In the same period, instead of the obsolete and physically worn herringbone reducers ZM-1600 and 40A7 for drive of mills $\varnothing 3 \times 14 \mathrm{~m}$, we developed the reducer $\mathrm{C} 3-1800$ with a total center distance of $\mathrm{As}=$ $900+1250+1800=3950 \mathrm{~mm}$. The reducer is powered by an engine with a power of $1600 \mathrm{~kW}$ and

a speed $1000 \mathrm{rpm}$. The total gear ratio is $\mathrm{u}_{\mathrm{s}} \approx 58.4$, the calculated torque on the input shaft is $15.6 \mathrm{kNm}$ with a permissible overload of 1.5 times. All gears were made of steel 38XH3MA with hardening of pinion teeth to a hardness of $277 \ldots 321 \mathrm{HB}$ and teeth of wheels to a hardness of $241 \ldots 285$ HB. The weight of the reducer is 82.5 tons. The gearbox can be installed on existing foundations without transferring the anchor bolts and the electric motor.

However, the new time makes new demands. Currently, only reducers belonging to the group of the 1st technical level (Table 1), that is, reducers with high-strength carburized gears can be competitive on the free market.

In this connection, instead of the C3-1800 reducer, we have developed a project of the reducer C3-1100C with the same load capacity. This project provides for the manufacturing of all gears from steel 20XH3A with carburization, hardening of the teeth to a hardness of $60 \mathrm{HRC}$ and their subsequent grinding. Gears with the increased hardness can be made not herringbone, but helical with a helix angle of $\beta=10^{\circ} 15^{\prime}$, which allows the use of tapered roller bearings in the shaft supports. The center distance between the stages decreases to Ac $=560+780+$ $1100=2440$, that is, 1.6 times. The diameter of the most problematic low-speed wheel was reduced from 2765 to $1770 \mathrm{~mm}$, and the width of the wheels was reduced by $1.5-2$ times compared to the total width of the herringbone gears. As a result, the mass of the reducer can be reduced to 45 tons.

\section{Drive reducer of cement mill $\varnothing 3.2 \times 15$}

One of the most powerful in the cement industry is the herringbone single-stage reducer CO-2400, produced by Volgocemmash, used in driving cement mills $\varnothing 3.2 \times 15$. The drive is carried out from an electric motor with a power of $2000 \mathrm{~kW}$ and a speed of $100 \mathrm{rpm}$. The weight of the reducer is 103 tons, of which 45 tons is the mass of a low-speed wheel with a diameter of $\varnothing 4144$. The estimated torque on the output shaft is $1120 \mathrm{kNm}$, gear ratios of two versions are $U=5.9$ and $U=5.53$. Volgocemmash produced 231 reducers of this size and as a result of physical wear and tear all of them either need or will soon need to be replaced.

The production on EZTM of such a reducer as a whole and of its low-speed wheel in particular causes serious technological difficulties and the need to transfer a significant part of the work to other enterprises on external cooperation. In this regard, our Design Department has developed two projects for the possible replacement of this reducer, which would focus on using the plant's own capacities, provide the required technical characteristics of the drive, reduce the weight and price of the gearbox, and its interchangeability with the CO-2400 type reducer in terms of main connecting sizes.

The comparative analysis of completed projects showed the following.

1. While maintaining the one-stage scheme of the reducer, optimization of geometrical parameters made it possible to reduce the center distance to $2100 \mathrm{~mm}$ and the diameter of the low-speed wheel to $3620 \mathrm{~mm}$, ensuring a corresponding reduction in the weght of the gearbox as a whole and the lowspeed wheel in particular. However, the reduction in size with respect to the CO-2400 reducer leads to the fact that its use to replace the drive of existing mills will require the Customer to replace the foundation or manufacture the intermediate frame.

2. Replacing a single-stage reducer with a two-stage C2-1560 with a sum of center distances $1132+1560$ $=2692$ and a V-shaped arrangement of shafts (Fig. 2) made it possible to keep the distance between the input and output shafts equal to the original. Such a reducer has a much higher probability of demand in the market for cement equipment drives. At the same time, the weight of the reducer is decreased to 80 tons versus 103 tons of the CO-2400, and the outer diameter of the low-speed wheel is reduced to 2,253 $\mathrm{mm}$, which will ensure the possibility of its manufacture on EZTM. 


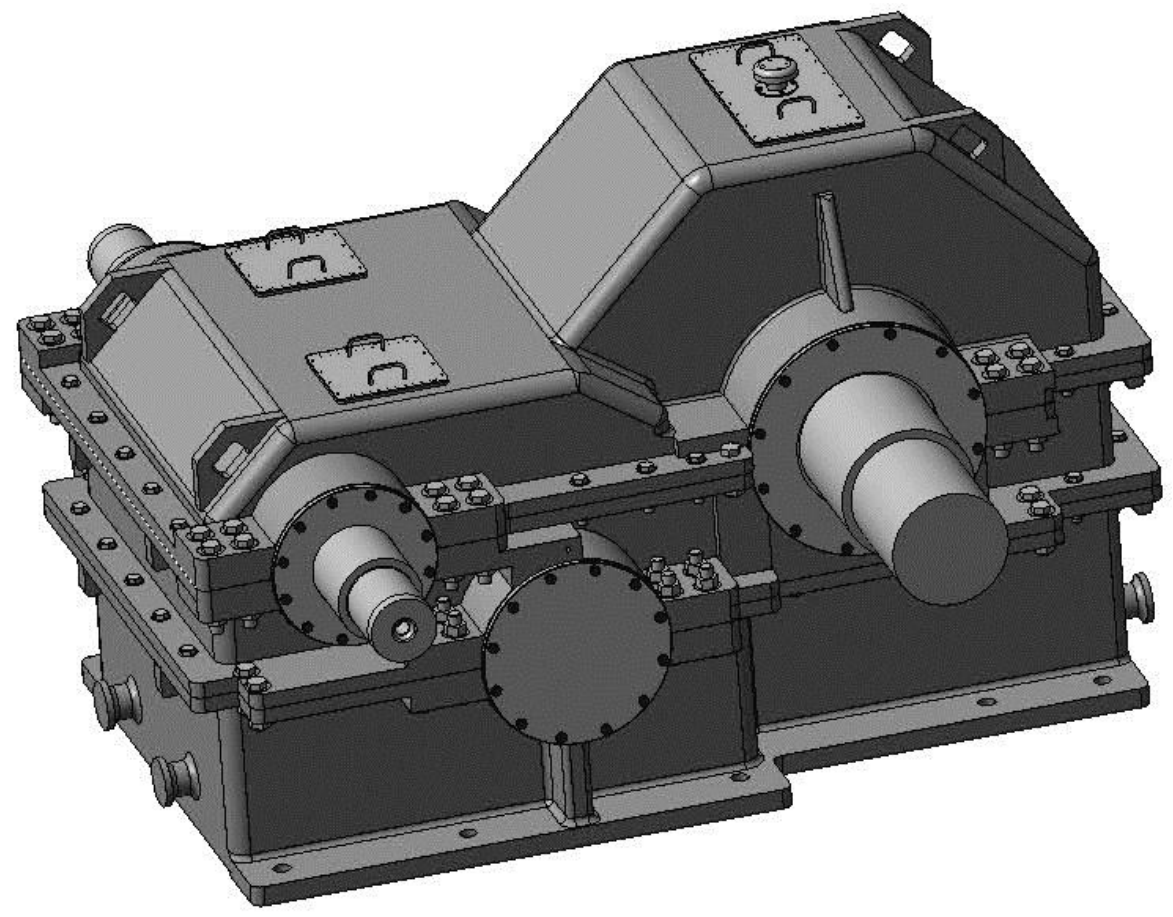

Fig. 2. Reducer C2-1560 for drive of cement mills Ø3.2x15.

\section{New reducer for cement mills drive}

One of the latest developments of EZTM for the cement industry is the reducer $\mathrm{C} 3-770$. This is a cylindrical three-stage gearbox with a sum of center distances $570+660+770=2000 \mathrm{~mm}$ and a weight of 14.5 tons. At the request of different customers, the reducer is available in two versions with gear ratios $u_{\mathrm{s}}=32$ and $\mathrm{u}_{\mathrm{s}}=30$. The gearbox is powered by an engine with a capacity of $\mathrm{N}=1,100 \mathrm{~kW}$ and a speed of $n_{1}=960 \mathrm{rpm}$. The estimated working life is 30,000 hours with a torque of $320 \mathrm{kNm}$ on the output shaft. The possibility of a short-term (up to $5 \%$ of the resource) double overload is allowed.

Gears are involute, helical, and modified. The helix angles of the teeth and the factors of addendum modification are optimized from the condition of ensuring the maximum torque allowed by contact endurance. All gear parts are made of chrome-nickel steel 20XH3A with carburizing, hardening of the teeth to a hardness of $54 \ldots 60$ $\mathrm{HRC}$ and their subsequent grinding.

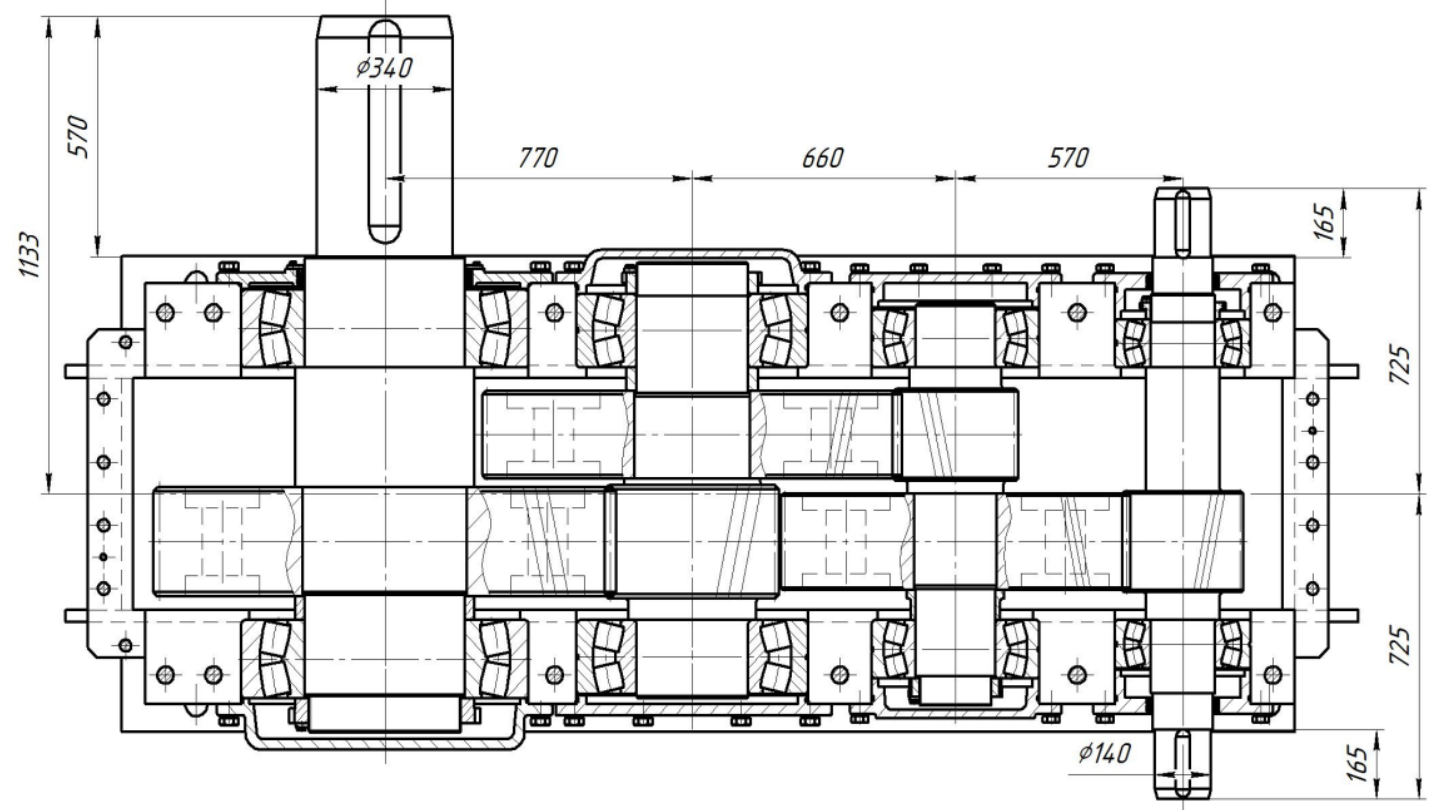

Fig. 3. Reducer C3-770 for drive of cement mills. 


\section{Conclusion}

For the purpose of high loaded multi-stage gearboxes of heavy equipment, in particular, for the cement industry to meet today's world level, two conditions must be met:

1. Optimization of the geometrical parameters of the gears, both between the stages, and within each of them;

2. Manufacturing of all gears with highly hard, carburized and ground teeth.

\section{References}

1. G..A. Snesarev. Optimal Design of Gear Reducers // Vestnik Mashinostrojenia, No 9, 1985, pp. 30-35 (in Russian)

2. A.A.Kovtushenko, S.A Lagutin, and V.V. Muntyan. Optimal Design of Metallurgical Reduction Gears // Journal of Machinery Manufacture and Reliability, No 6, 1993, pp. 24-28.

3. S. Lagutin, S. Chirkov, and A. Klochkov. Third Generation of Apron Feeder Drives, // Proc. of the 8-ht Internat. Congress "Machines, Technologies, Materials", Varna, Bulgaria, 2011, pp. $26-27$.

4. E.A.Gudov, S.A.Lagutin, and S.V. Morozov. New gear drives for concentrating and cement equipment // Vestnik NTU "KhPI”, № 36, Kharkov, 2012, pp. 46-52.

5. S. Lagutin, E. Gudov, and A. Klochkov. Reducers for Main Drives of Rolling Mills // Machine Design, vol. 5(2013), No.2, ISSN 1821-1259, pp 79-82.

6. V.I. Goldfarb and A.A. Tkachev. Design of Involute Helical Gears. New Approach // Izhevsk: Publishing house IzhSTU, 2004. - 94 p. (in Russian)

7. H. Blossfeld and A. Gzhibovski. Drives of Ball Mills // Cement and its application. №3, 2011, pp. 123-125. (in Russian) 